\title{
Association of C-Reactive Protein Level and Short Term Clinical Outcome among Spontaneous Intracerebral Haemorrhage Patients
}

\author{
Md. Mamnur Rashid', Chandra Shekhar Bala², Mohammad Shah Jahirul Hoque Chowdhury³, \\ Mohammad Selim Shahi ${ }^{4}$, Md. Merazul Islam Shaikh ${ }^{5}$, Mohammad Akter Hossain ${ }^{6}$, \\ Md. Habibur Rahman \\ ${ }^{1}$ Resident Physician, Department of Neurology, National Institute of Neurosciences \& Hospital, Dhaka, Bangladesh; ${ }^{2}$ Junior \\ Consultant, Emergency Department, National Institute of Neurosciences \& Hospital, Dhaka, Bangladesh; ${ }^{3}$ Associate \\ Professor, Department of Neurology, National Institute of Neurosciences \& Hospital, Dhaka, Bangladesh; \\ ${ }^{4}$ Associate Professor, Department of Neurology, National Institute of Neurosciences \& Hospital, Dhaka, \\ Bangladesh; ${ }^{5}$ Junior Consultant (Medicine), Department of Neurology, National Institute of \\ Neurosciences \& Hospital, Dhaka, Bangladesh; ${ }^{6}$ Assistant Professor, Department of Neurology, \\ National Institute of Neurosciences \& Hospital, Dhaka, Bangladesh; ${ }^{7}$ Assistant Professor, \\ Department of Physical Medicine, Rangpur Medical College, Rangpur, Bangladesh
}

[Received: 21 February 2017; Revised: 6 March 2017; Accepted: 11 May 2017; Published: 1 July 2017]

\begin{abstract}
Background: C-reactive protein is a biomarker among the spontaneous intracerebral haemorrhage patients. Objective: The purpose of this present study was to see the association of CRP level with the short term clinical outcome among spontaneous intracerebral haemorrhage patients. Methodology: This prospective cohort study was conducted in the Department of Neurology at Dhaka Medical College and Hospital, Dhaka, Bangladesh from July 2012 to June 2014 for a period of two (02) years. Patients presented with first ever spontaneous intracerebral haemorrhage with the age group of more than or equal to 18 years with both sexes and hospital admission within 48 hours of onset were included for this study. Admission plasma CRP was measured and study population were divided into group I (plasma CRP $\geq 6 \mathrm{mg} / \mathrm{L}$ ) and group II (plasma $\mathrm{CRP}<6 \mathrm{mg} / \mathrm{L}$ ). The patients were observed daily till 1 week after admission with special attention to vital parameters and clinical outcome which were mortality, functional outcome and early neurological worsening. Finally findings were analyzed and clinical outcome were compared in patient with different level of admission plasma CRP. Result: Early neurological worsening at the end of first week was 37(38\%) patients. Poor functional outcome (GOS 2-3) at the end of first week was found in 51(52\%) patients. Overall mortality within that period was 16(17\%) patients. Elevated CRP level was associated with higher proportion of GCS score $<9$ at day seven. Early neurological worsening and poor functional outcome (GOS2-3) was also found more in these patients. Conclusion: High admission plasma CRP level may be associated with higher proportions of poor short term outcome (GOS 2-3), early neurological worsening at the end of the first week after onset and mortality within this period in the patients with spontaneous intracerebral haemorrhage. [Journal of National Institute of Neurosciences Bangladesh, 2017;3(2): 89-93]
\end{abstract}

Keywords: spontaneous intracerebral haemorrhage; Stroke; C-reactive protein; clinical outcome

Correspondence: Dr. Md. Mamnur Rashid, Resident Physician, Department of Neurology, National Institute of Neurosciences \& Hospital, Sher-E-Bangla Nagar, Agargaon, Dhaka, Bangladesh; Email: dr.mrashidfmc@gmail.com; cell no.: +8801711073653

Conflict of Interest: The authors of this paper have declared that there is no conflict of interest to any of the authors.

Contributions to Authors: Rashid MM involved in the protocol preparation, data collection, study procedure conduction and analysis of data up to report writing. Bala CS, Choudhury MSJH, Shahi MS, Shaikh MMI, Hossain MA, Rahman MH were involved in writing of the manuscript and revision of the manuscript. All the authors have read and approved the final version of the manuscript. Funding: This study has been performed without any funding from outside else.

How to cite this article: Rashid MM, Bala CS, Choudhury MSJH, Shahi MS, Shaikh MMI, Hossain MA, Rahman MH. Association of C-Reactive Protein Level and Short Term Clinical Outcome among Spontaneous Intracerebral Haemorrhage Patients. J Natl Inst Neurosci Bangladesh, 2017;3(2): 89-93

Copyright: (2017. Rashid et al. Published by Journal of National Institute of Neurosciences Bangladesh. This article is published under the Creative Commons CC BY-NC License (https://creativecommons.org/licenses/by-nc/4.0/). This license permits use, distribution and reproduction in any medium, provided the original work is properly cited, and is not used for commercial purposes.

\section{Introduction}

Inflammation is a major feature of spontaneous intracerebral hemorrhage ( $\mathrm{sICH})$ pathology $^{1}$ and involved in the progression of brain injury after $\mathrm{SICH}^{2}$. 
Inflammatory markers on admission, such as fever, elevated white blood cell (WBC) count, interleukin-6 (IL-6), and fibrinogen are associated with worse short-term outcome ${ }^{3}$. Pathologic mechanisms include immunologic, endothelial dysfunction, and coagulopathy, contributing to morbidity and mortality ${ }^{4}$. Increased C-reactive protein (CRP) has been shown previously to relate to poor outcome after $\mathrm{sICH}^{5}$. C-reactive protein (CRP), an acute-phase reactant induced by IL-6, is associated with 30-day mortality in ICH patients ${ }^{6}$.

Several prospective studies in ischemic stroke patients have reported that increased levels of acute inflammatory markers, such $\mathrm{CRP}^{7}$ and white blood cell (WBC) count $^{8}$ are associated with increased risk of death or disability. The prognostic role of these inflammatory markers after sICH is less clear9. Early neurologic worsening (ENW) in patients with ICH is generally thought to be due to enlargement of the hemorrhage or development of hydrocephalus, whereas late deterioration is linked to perilesional edema ${ }^{10}$. Among the factors related to the poor prognosis of $\mathrm{ICH}$ is the size of the hemorrhage itself, intracranial hypertension with cerebral tissue displacement and herniation, and cellular death that occurs hours or days later in the tissues surrounding the hematoma ${ }^{11}$.

Potential limitations of previous studies of inflammatory markers in sICH include the possibility that the systemic acute-phase response may have been attributable to accompanying infection in some cases, and that the inflammatory and CRP response could still be evolving. Additionally, changes in CRP levels after acute sICH have not been analyzed in detail, yet these may be more reflective of the inflammatory response to sICH. Therefore, the primary aim of my study was to evaluate the kinetics of plasma CRP concentrations after acute $\mathrm{sICH}$ and the relationship with short term clinical outcome.

\section{Methodology}

This was prospective cohort study which was conducted in the Department of Neurology at Dhaka Medical College and Hospital, Dhaka, Bangladesh from July 2012 to June 2014 for a period of two (02) years. Patients with spontaneous intracerebral haemorrhage admitted in the departments of Neurology, Neurosurgery and Medicine, Dhaka Medical College and Hospital, Dhaka, Bangladesh were taken as study population. Patients presented with first ever spontaneous intracerebral haemorrhage with the age group of more than or equal to 18 years with both sexes and hospital admission within 48 hours of onset were included for this study. Patients with haematoma secondary to head injury, patients of ischaemic stroke and subarachnoid haemorrhage, patients underwent surgical or interventional procedure, unable to confirm by CT-scan of head, patients presented with serious co-morbidity like chronic kidney disease, heart failure, decompensated chronic liver disease, respiratory failure and metabolic encephalopathy and infection were excluded from this study. Those with sICH were selected for the study, after getting the informed consent. The basic demographic variables and important vascular risk factors were recorded. A detailed history was taken and a meticulous neurological examination was performed in every patient. Patients were considered to have hypertension when there was reliable history of hypertension, hypertensive retinopathy on examination or features of left ventricular hypertrophy in ECG. CT scan of head was done on every patient at the department of radiology and imaging of Dhaka Medical Collegeas early as possible for confirmation of spontaneous intracerebral hemorrhage. Admission plasma CRP was measured in every patient by nephelometric system by using commercial kit (DADE BEHRING BN 100, USA) in the Department of Microbiology, Dhaka Medical Collegeand study population were divided into group I (plasma CRP $\geq 6 \mathrm{mg} / \mathrm{L}$ ) and group II (plasma CRP $<6$ $\mathrm{mg} / \mathrm{L}$ ). All the patients received the standard medical management of spontaneous ICH according to the guideline of American Heart Association and American Stroke Association (Morgenstern 2010), as far as practicable. In all patients the plasma CRP concentration was measured within 6 hours of admission (median, 120 minutes) at the time of first blood drawing and before any procedure. The patients were observed daily till 1 week after admission with special attention to vital parameters and clinical outcome which were mortality, functional outcome and early neurological worsening. The patients were observed daily during the first week after onset with special attention to vital parameters like pulse, blood pressure, temperature, respiratory rate and neurological features. The functional outcome and early neurological worsening at the end of first week and any mortality within this period were taken as outcome. GOS 2 to 3 , early neurological worsening like deterioration of GCS score by 2 or more at the end of first week and mortality within that period was taken as poor outcome. Finally findings were analyzed and clinical outcome were compared in patient with different level of admission plasma CRP. The analyses were performed by using 
standard statistical procedures. SPSS version 20.0 were utilized whenever required and also to cross-check the results. The mortality among patients with $\mathrm{C}$-reactive protein positive/elevated $(\geq 6 \mathrm{mg} / \mathrm{L}$ ) was compared to that of patients with $\mathrm{C}$-reactive protein negative/normal $(<6 \mathrm{mg} / \mathrm{L})$. Early neurological worsening and functional outcome were compared in the same manner. Results were expressed in odds ratio at $95 \%$ confidence interval and were considered significant if $p$ value comes 0.05 or less. Prior to the commencement of this study, the research protocol was approved by the Research Review Committee.

\section{Results}

The present study was undertaken to test hypothesis that spontaneous intracerebral haemorrhage patients with high admission plasma C-reactive protein usually carry adverse in-hospital short term outcome. To that end a total of 100 patients of sICH with predefined enrollment criteria were included in the study and were subjected test for admission plasma C-reactive protein along with other necessary tests but two patients were dropped due to inadequate follow-up. So, 98 patients were included for the final analysis, of them 37 had plasma $\mathrm{C}$ - reactive protein $<6 \mathrm{mg} / \mathrm{L}$ and were consider as normal/negative and the rest 61 had plasma

Table 1: Baseline Prognostic Variables of Study Subjects at Admission ( $\mathrm{n}=98)$

\begin{tabular}{llcc}
\hline Characteristics & CRP Positive & CRP Negetive & P-value \\
\hline Age (years) \# & $65.7 \pm 11.9$ & $61.4 \pm 16.6$ & $0.14^{*}$ \\
Male sex & $34(55.7)$ & $24(64.9)$ & $0.37^{* *}$ \\
SBP, mm Hg \# & $159.6 \pm 23.6$ & $166.3 \pm 21.9$ & $0.33^{*}$ \\
DBP, mm Hg \# & $100.5 \pm 24.4$ & $104.8 \pm 22.9$ & $0.34^{*}$ \\
GCS score $<9$ & $32(52.5)$ & $20(54.05)$ & $0.87^{* *}$ \\
Glucose, mmol/L \# & $7.8 \pm 1.6$ & $7.9 \pm 1.7$ & $0.74^{*}$ \\
WBC $>11,000 /$ cu mm & $44(72.1)$ & $29(78.3)$ & $0.49^{* *}$ \\
ICH volume $>60$ cc & $9(14.8)$ & $4(10.8)$ & $0.58^{* *}$ \\
Midline shift $(>10$ mm) & $11(18.0)$ & $5(13.5)$ & $0.56^{* *}$ \\
Ventricular extension & $12(19.7)$ & $7(18.91)$ & $0.93^{* *}$ \\
\hline
\end{tabular}

Percentages are mentioned within parentheses;\# Mean \pm standard deviation; ${ }^{*}$ Student's unpaired T-test; $* *$ Chi-square test

Table 2: Distribution of Overall Outcome of The Study Subjects at the end of first week $(n=98)$

\begin{tabular}{|c|c|c|c|c|}
\hline Admission CRP (mg/L) & Early Neurological worsening & Poor Functional Outcome & Mortality & Total \\
\hline CRP Positive $(\geq 6)$ & $30(49.18)$ & $38(62.29)$ & $14(22.95)$ & $61(62.24)$ \\
\hline CRP Negative $(<6)$ & $07(18.91)$ & $13(35.13)$ & $02(5.40)$ & $37(37.75)$ \\
\hline Total & 37(37.75) & $51(52.04)$ & $16(17.34)$ & 98 \\
\hline
\end{tabular}

Percentages are mentioned within the parentheses; Early neurological worsening= Deterioration of GCS $\geq 2 /$ more; Poor Functional Outcome $=$ GOS 2 to 3

Table 3: Association of admission C-reactive protein level with outcome $(n=98)$

\begin{tabular}{|c|c|c|c|c|c|c|}
\hline \multirow{2}{*}{$\begin{array}{l}\text { Outcome } \\
\text { (at the end of first week) }\end{array}$} & & \multicolumn{2}{|c|}{ Admission CRP } & \multirow{2}{*}{$\begin{array}{c}\text { Relative } \\
\text { risk }\end{array}$} & \multirow[t]{2}{*}{$95 \% \mathrm{CI}$} & \multirow[t]{2}{*}{ P-value } \\
\hline & & Positive $(\mathrm{n} 1=61)$ & Negative $(\mathrm{n} 2=37)$ & & & \\
\hline \multirow[t]{2}{*}{ GCS score } & $<9$ & $40(66)$ & $12(32)$ & 2.02 & $1.23-3.33$ & $0.001 *$ \\
\hline & $\geq 9$ & $21(34)$ & $25(68)$ & & & \\
\hline \multirow[t]{2}{*}{ Early neurolog worsening } & Yes & $30(49)$ & $7(19)$ & 2.60 & $1.27-5.31$ & $0.003 *$ \\
\hline & No & $31(51)$ & $30(81)$ & & & \\
\hline \multirow[t]{2}{*}{ Functional outcome } & Poor & $38(81)$ & $13(37)$ & 2.18 & $1.38-3.42$ & $<0.001 *$ \\
\hline & Good & $9(19)$ & $22(63)$ & & & \\
\hline \multirow[t]{2}{*}{ Mortality } & Dead & $14(23)$ & $2(5)$ & 4.26 & $1.02-17.64$ & $0.02 *$ \\
\hline & Alive & $47(77)$ & $35(95)$ & & & \\
\hline
\end{tabular}

Percentages are mentioned within parenthesis; ${ }^{*}$ Chi-square test; Poor $=$ GOS2-3; Good=GOS4-5; Positive $=\geq 6$; Negative=<6; neurology=meurology 
C-reactive protein $\geq 6 \mathrm{mg} / \mathrm{L}$ and were considered as having elevated/positive admission C-reactive protein.In-hospital short term outcome (mortality, functional outcome and early neurological worsening) were then compared between the two groups.

Table 1 shows the important baseline prognostic variables of study subjects at admission. No significance difference was found in the baseline prognostic variables between the CRP positive and CRP negative groups.

Table 2 shows the overall outcome of spontaneous ICH patients in this study. Early neurological worsening at the end of first week was $37(38 \%)$ patients. Poor functional outcome (GOS 2-3) at the end of first week was found in 51(52\%) patients. Overall mortality within that period was $16(17 \%)$ patients. In hospital functional outcome were observed more adverse in elevated/ positive CRP group at the end of first week and mortality was also observed higher in CRP positive group than CRP negative within that period.

Table 3 compares the proportion of GCS score $<9$ and Glasgow outcome scale at the end of first week, and early neurological worsening, functional outcome and mortality within that period between CRP positive and negative groups. Elevated CRP level was associated with higher proportion of GCS score $<9$ at day seven. Early neurological worsening and poor functional outcome (GOS2-3) was also found more in these patients. Higher mortality was observed too in these patients. Among the patients who survived the first week, the proportion of CRP positive was also higher.

\section{Discussion}

Stroke is the second leading cause of death among the non communicable diseases worldwide and the leading cause of long term disability ${ }^{7}$. Overall incidence of ICH is approximately 0.25 per 1000 person-years, higher in the Asians 0.5 per 1000 person-year ${ }^{11}$. Spontaneous ICH is often a devastating clinical event with limited effective therapies. Inflammation is a major feature of sICH pathology, and involve in the progression of brain injury after $\mathrm{sICH}^{9}$. Increased CRP has been shown previously to relate to poor outcome after sICH. CRP is an acute-phase reactant induced by IL- 6 which is also associated with 30 -day mortality in $\mathrm{sICH}$ patients ${ }^{5}$. Most of the studies regarding this issue have been conducted in the western countries. In Bangladesh short term outcome in ischemic stroke was studied by CRP response but no such type of study has been conducted in Bangladesh. Considering all these circumstances, C-reactive protein responses on admission after sICH is studied to find out any association with short term clinical outcome and mortality within seven days.

Ninety eight patients of spontaneous intracerebral haemorrhage (ICH) were included in this study. Most $(84 \%)$ of the patients were of 50 years or more age. Mean ( \pm standard deviation) age was $64.01 \pm 13.90$ years. The age distribution was similar to that of most of the previous studies conducted in Bangladesh and India ${ }^{12-14}$. The youngest and oldest patients were of 20 and 80 years respectively. Number of males $(60 \%)$ was more than that of females (40\%). Similar sex distribution was found in the study on spontaneous ICH patients in Heerlen, Netherlands ${ }^{15}$.

C-reactive protein level was found to be elevated/CRP positive in $62 \%$ patients and not elevated/CRP negative in $38 \%$ patients out of 98 patients. Median CRP was $8.0 \mathrm{mg} / \mathrm{L}(\mathrm{R}, 4-16 \mathrm{mg} / \mathrm{L})$. These findings are almost consistent with the study conducted by Napoli 2014. Median CRP was $9(\mathrm{R}, 7-16) \mathrm{mg} / \mathrm{L}$ in the poor functional outcome (GOS 2-3) group which was significant $(\mathrm{P}<0.001)$. CRP was also significantly higher $(\mathrm{P}=0.003)$ in early neurological worsening patients was $9(\mathrm{R}, 7-16 \mathrm{mg} / \mathrm{L})$ compared with stable or improving patients.

Baseline prognostic variables of study subjects at admission, SBP $159.6 \pm 23.6 \mathrm{~mm} \mathrm{Hg}$, DBP $100.5 \pm$ $24.4 \mathrm{~mm} \mathrm{Hg}$, GCS score $<9$ in 53\%, Glucose $7.8 \pm 1.6$ $\mathrm{mmol} / \mathrm{L}, \mathrm{WBC}>11,000 / \mathrm{cu} \mathrm{mm}$ in $72 \%$, ICH volume $>60 \mathrm{cc}$ in $15 \%$, Midline shift $(>10 \mathrm{~mm})$ in $18 \%$ and Ventricular extension in 20\% respondents were found respectively in CRP positive tertile none of these were statisticaly significant in comparison to CRP negetive terile.

Regarding outcome, early neurological worsening at the end of first week was $38 \%$ patients which was higher than the study conducted by Napoli et $\mathrm{al}^{16}$. Insufficient advanced stroke care facilities might be the reason behind higher early neurological worsening in this series. Poor functional outcome (GOS 2-3) at the end of first week was found in $52 \%(n=51)$ patients. Similar finding was observed in studies on spontaneous intracerebral haemorrhage patients conducted by Napoli et $\mathrm{a}^{16}$. Overall mortality within that period was $17 \%$ patients which was lower to Napoli et $\mathrm{l}^{6}$. Small sample size, short duration and less severe initial presentation of the respondents might be the reason behind lower mortality in this series.

The focus of this study, admission plasma CRP level $\geq$ $6 \mathrm{mg} / \mathrm{L}$ and $<6 \mathrm{mg} / \mathrm{L}$ were found in $62 \%$ and $38 \%$ patients respectively, which is almost consistent with 
Napoli et $\mathrm{al}^{16}$. In terms of outcome, patients with higher plasma CRP level $\geq 6 \mathrm{mg} / \mathrm{L}$ had increased mortality and poor functional outcome (GOS 2-3) andearly neurological worsening than the patients with plasma CRP level $<6 \mathrm{mg} / \mathrm{L}$. Similar findingwas observed in a study conducted by Napoli et $\mathrm{al}^{6}$ in Italy. Patients with high admission plasma CRP were found to carry 4.6 times $(95 \% \mathrm{CI}=1.02-17.64)$ higher risk of mortality, 2.57 times $(95 \% \mathrm{CI}=1.27-5.31)$ higher risk of early neurological worsening and 2.18 times $(95 \% \mathrm{CI}=1.38-3.42)$ higher risk of poor functional outcome (GOS 2-3) than those who had lower admission plasma CRP level. But mortality was lower than that of a study by Napoli et al6 and Napoli et $\mathrm{a}^{16}$. This descripency was probably due tosmall sample size, short duration and less severe initial neurological deficit of the cases in this seris. Poor functional outcome (GOS 2-3) of the present study was consistent with finding of Napoli et $\mathrm{al}^{6}$. Early neurological worsening at the end of first week was higher than the study conducted by Napoli et $\mathrm{al}^{16}$. Insufficient advanced stroke care facilities might be the reason behind higher early neurological worsening in this series. A similar relation between admission plasma CRP level and short- term outcome has been observed in 223 patients in Italy by Napoli et $\mathrm{al}^{6}$.

In this research, it was found that patients with highest tertile of admission plasma CRP were found to carry 4.6 times $(95 \% \mathrm{CI}=1.02-17.64)$ higher risk of mortality and 2.18 times $(95 \% \mathrm{CI}=1.38-3.42)$ higher risk of poor functional outcome(GOS 2-3) than those who had lowest tertile admission plasma CRP level. It also revealed that 2.57 times $(95 \% \mathrm{CI}=1.27-5.31)$ higher risk of early neurological worsening in the patient with highest tertile of admission plasma CRP.

\section{Conclusion}

High admission plasma CRP level may be associated with higher proportions of poor short term outcome (GOS 2-3), early neurological worsening at the end of the first week after onset and mortality within this period in the patients with spontaneous intracerebral haemorrhage. Therefore, the hypothesis of this study is proved. Thus, admission plasma CRP can be used as a reliable predictor of poor short term outcome, early neurological worsening and mortality in patients with spontaneous intracerebral haemorrhage. This may assist patient care and prognostication and may be useful in selecting patients for trials ofanti-inflammatory therapies aimed at preventing early neurological worsening and mortality and thus improving clinical outcome. Admission plasma CRP can be used as reliable predictor of short term clinical outcome in spontaneous intracerebral haemorrhage.

\section{References}

1. Silva, Y, Leira, R, Tejada, J, Lainez, JM, Castillo, J, Dávalos, A 2005, 'Stroke Project, Cerebrovascular Diseases Group of the Spanish Neurological Society. Molecular signatures of vascular injury are associated with early growth of intracerebral hemorrhage'. Stroke, vol. 36, pp.86-91.

2. Aronowski, J, Zhao, X2011, 'Molecular pathophysiology of cerebral hemorrhage: secondary brain injury'. Stroke, vol. 42, pp. 1781-1786.

3. Leira, R, Dávalos, A, Silva, Y, Gil-Peralta, A, Tejada, J, Garcia, M, et al.2004, 'Stroke Project, Cerebrovascular Diseases Group of the Spanish Neurological Society. Early neurologic deterioration in intracerebral hemorrhage: predictors and associated factors'. Neurology, vol. 63, pp. 461-467.

4. Malham, GM, Souter, MJ.2001,'Systemic inflammatory response syndrome and acute neurological disease'.Br J Neurosurgery,vol.15, pp.381-387.

5. Castellanos, M, Leira R, Tejada J, Gil-Peralta A, Davalos A, Castillo J. 2005, 'Predictors of good outcome in medium to large spontaneous supratentorialintracerebralhaemorrhages'. J NeurolNeurosurg Psychiatry, vol.76, pp.691-695.

6. Napoli, MD, Papa, F,Bocola, V 2001, 'Prognostic influence of increased C-reactive protein and fibrinogen levels in ischemic stroke'.Stroke, vol.32, pp.133-8.

7. Steiner, T, Kaste, M, Forsting, M, Mandelow, D, Kwecinski, H, Szikora, I 2006, 'Recommendation for the management of intracranial hemorrhage, part-I: Spontaneous intracerebral hemorrhage'.Cerebrovascular diseases,vol. 22(4), pp.294-316.

8. Graeb, DA, Robertson, WD, Lapointe, JS, Nugent, RA, Harrison, PB1982, 'Computed tomographic diagnosis of intraventricular hemorrhage. Etiology and prognosis'. Radiology, vol. 143, pp. 91-96.

9. Kothari, RU, Brott, T, Broderick, JP, Barsan, WG, Sauerbeck, LR, Zuccarello, et al.1996, 'The ABCs of measuring intracerebral hemorrhage volumes'. Stroke, vol. 27,pp. 1304-1305.

10. Mayer, S, Sacco, RL, Shi, T, Mohr, JPL1994, 'Neurological deterioration in non comatose patients with supratentorialintracerebral hemorrhage'. Neurology, vol. 44, pp.1379-1384

11. Tuhrim, S, Horowitz, DR, Sacher, M, Godbold, JH. 1995, 'Validation and comparison of models predicting survival following intracerebral hemorrhage'.Crit Care Med, vol. 23, pp. 950-954 12. Siddique MAN, Nur Z, Mahbub MS, Alam, MB,Miah, MT 2009 , 'Clinical presentation and epidemiology of stroke - a study of 100 cases'. Journal of Medicine, vol.10 (2), pp. 86-89

13. Nag, C, Das, K, Ghosh, M,Khandakar, MR 2012,'Prediction of clinical outcome in acute haemorrhagic stroke from a single CT scan on admission'. North American Journal of Medical Sciences,vol. 4(10), pp. 463-467

14. Mollah, AS, Rahman, SW, Das, KK,Hassanuzzaman, M. 2007, 'Characteristics of patients admitted with stroke'. Mymensingh Medical Journal, vol. 16(1), pp. 20-24

15. Franke, CL, van, SJC, Van, GJ 1992, 'Prognostic factors in patients with intracerebralhaematoma'. Journal of Neurology Neurosurgery and Psychiatry, vol. 55(8),pp 653-657

16. Napoli, MD, Godoy, DA, Campi, V, Masotti, L, Smith, CJ, Parry Jones, AR, et al. 2012, 'C-reactive protein in intracerebral hemorrhage: time course, tissue localization, and prognosis'. Neurology, vol.79, pp. 690-699 